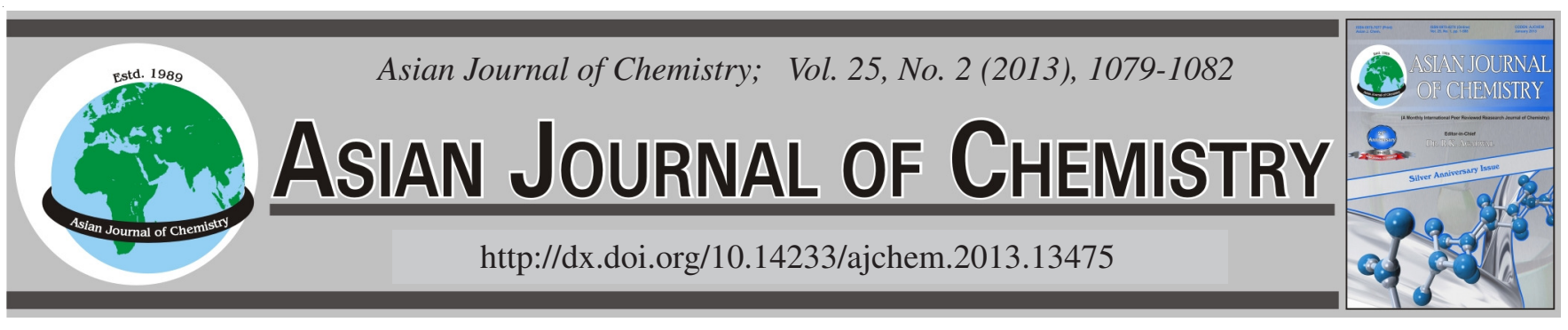

\title{
Spectrophotometric Determination of Paracetamol and Orphenadrine Citrate in Tablet
}

\author{
Leon Nejem, SaAd Antakli* and Helen Bagdashe
}

Department of Chemistry, Faculty of Science, University of Aleppo, Aleppo, Syria

*Corresponding author: E-mail: antakli@scs-net.org

\begin{abstract}
A simple and rapid spectrophotomitric method has been developed to determine orphenadrine citrate and paracetamol in tablet formulations. The first step was based on the reaction of orphenadrine citrate with 1-amino naphthalene and sodium nitrite with heating for 6 min at 50 ${ }^{\circ} \mathrm{C}$ to give an orange colour having a maximum absorbance at $462 \mathrm{~nm}$. The optimization of the reaction conditions is investigated. In the second step, paracetamol was analyzed after solving it in distilled water by taking the first order derivative spectroscopy and that to eliminate spectral interference with orphenadrine citrate. Beers law is obeyed in the concentration ranges $4.61-80.76 \mu \mathrm{g} / \mathrm{mL}$ and $0.75-30$ $\mu \mathrm{g} / \mathrm{mL}$ for orphenadrine citrate and paracetamol, respectively. The molar absorptivity, limit of detection, limit of quantification, Sandell sensitivity and linearity are also calculated. The average per cent recovery was found to be $99.90 \pm 0.14 \%$ for paracetamol and $99.80 \pm$ $0.05 \%$ for orphenadrine citrate.
\end{abstract}

Key Words: Paracetamol, Orphenadrine citrate, Spectrophotomitric method.

\section{INTRODUCTION}

Orphenadrine citrate is chemically [(RS)-(dimethyl-2-(2methyl-benzhydroxy)ethyl)amine citrate $\left(\mathrm{C}_{18} \mathrm{H}_{23} \mathrm{NO} \cdot \mathrm{C}_{6} \mathrm{H}_{8} \mathrm{O}_{7}\right.$, m.w. $461.5 \mathrm{~g} / \mathrm{mol}$ )] (Fig. 1-I), white or almost white, crystalline powder. Sparingly soluble in water, slightly soluble in alcohol. It contains not less than $98.5 \%$ and not more than $101 \%$ in its bulk powder ${ }^{1}$. It is most widely employed as skeletal muscle relaxant. It acts centrally by depressing the appropriate neurons to prevent the generation of somatic molar nerve impulses.

Paracetamol is 4-hydroxyacetanilide; $\mathrm{N}$-(4-hydroxyphenyl)acetamide (Fig. 1-II), white odorless crystalline powder, sparingly soluble in water, freely soluble in alcohol, very slightly soluble in methylene chloride. It contains not less than $99 \%$ and not more than $101 \%$ in its bulk powder ${ }^{1}$. It is a $p$-aminophenol derivative having analgesic and antipyretic properties and does not possess antiinflammatory activity. Combination of paracetamol and orphenadrine citrate shows an analgesic, antipyretic and skeletal muscle relaxing efficacy. Several methods have been applied in the literature for the determination of orphenadrine citrate and paracetamol in dosage forms and in biological fluids. Techniques such as spectrophotometry ${ }^{2-8}$, capillary electrophresis ${ }^{9}$, high performance liquid chromatography (HPLC) ${ }^{10-13}$, FT-Raman spectroscopy ${ }^{14}$, flow-injection spectroscopic ${ }^{15}$ and fluorescence spectroscopy ${ }^{16}$ are reported in the literature for the estimation of paracetamol.
The concentration of orphenadrine citrate is almost 13 times lesser than paracetamol in its formulations and so simultaneous estimation would have much interference. To overcome this, we presented a new spectrophotometric method for determination of paracetamol and orphenadrine citrate. In order to determine paracetamol, the first order derivative was selected at $264.17 \mathrm{~nm}$, while orphenadrine citrate was determined by forming an orange complex, resulting by the reaction of orphenadrine citrate with 1-amino naphthalene and sodium nitrite after heating for $6 \mathrm{~min}$ at $50{ }^{\circ} \mathrm{C}$ to give an orange colour having a maximum absorbance at $462 \mathrm{~nm}$.<smiles>Cc1ccccc1C(OCCN(C)C)c1ccccc1</smiles><smiles>CC(=O)Nc1ccc(O)cc1</smiles>

Fig. 1. I-Structure of Orphenadrine citrate

II-Structure of paracetamol

\section{EXPERIMENTAL}

In this study, we used UV-visible double beam spectrophotometer T-80/T80+ (England), quartz cells $1 \mathrm{~cm}$, analytical balance TE64 Sartorious sensitivity $0.01 \mathrm{mg}$. Digital water bath, pH meter (Inolap-Germany). Pipettes product of HGB (Germany). All chemicals were of analytical grade, sodium hydroxide, sodium acetate three hydrates, 1 -amino naphthalene 
and sodium nitrite (BDH Company), ethanol (Merck, Germany), bi-distillated water.

Drug products: We determined the quantity paracetamol and orphenadrine citrate 500 and $35 \mathrm{mg} /$ tablet, respectively in some Syrian products, trade names: Tranpal (Amrit), Asiagesic (Asia) and Myoflex (syphco).

\section{Reagents preparation}

Paracetamol and orphenadrine citrate stock solutions: The stock solutions of two drugs $1 \times 10^{-3} \mathrm{~mol} / \mathrm{L}$ were prepared separately by dissolving a suitable amount of drug powder in bi-distilled water at a boiling water bath for 5-10 min until complete dissolution of the analyte.

Reagent stock solution: 1 - Amino naphthalene $2 \times 10^{-3}$ $\mathrm{mol} / \mathrm{L}$ was prepared by dissolving a suitable amount in $2 \mathrm{~mL}$ ethanol in $100 \mathrm{~mL}$ volumetric flask and then completing to volume with bi-distilled water.

Sodium nitrite $1 \times 10^{-1} \mathrm{~mol} / \mathrm{L}$ was also prepared by dissolving a suitable amount in bi-distilled water.

\section{RESULTS AND DISCUSSION}

Orphenadrine citrate analysis: Orphenadrine citrate reacts with 1-amino naphthalene and sodium nitrite solution with heating at $50{ }^{\circ} \mathrm{C}$ for 6 min to give an orange complex. The result solution was scanned in the range of wavelengths $300-600 \mathrm{~nm}$ against a blank of bi-distilled water and then measured the absorbance at maximum wavelength $462 \mathrm{~nm}$. The linearity was in the concentration range 4.61-80.76 $\mu \mathrm{g} / \mathrm{mL}$. Molar absortivity coefficient was $12161 \mathrm{~L} \mathrm{~mol}^{-1} \mathrm{~cm}^{-1}$. Limit of detection and limit of quantification were 0.89 and $2.7 \mu \mathrm{g} / \mathrm{mL}$, respectively. Sandell sensitivity was $0.029 \mu \mathrm{g} / \mathrm{cm}^{2}$. We studied all the parameters of the coloured result solution to obtain the optimal conditions as the following:

Effect of temperature and time: We studied the effect of the temperature degree between $30-70{ }^{\circ} \mathrm{C}$ and heating time between 1 to $15 \mathrm{~min}$. It is found that at $30,35,40$ and $45^{\circ} \mathrm{C}$ the absorbance continued in rising. Above of that, at 55 and $60{ }^{\circ} \mathrm{C}$, the absorbance stayed constant, whereas at 65 and $70{ }^{\circ} \mathrm{C}$ a shifting peak has started and the absorbance decreased. So the optimum temperature was $50^{\circ} \mathrm{C}$ for 6 min heating.

Sequence of addition and stability: The most favourable addition sequence was "1-amino naphthalene-sodium nitritedrug" for obtaining the highest absorbance. The complex stability was at least $24 \mathrm{~h}$.

Effect of reagent volume: To study the 1-amino naphthalene volume influence on the coloured solution, we made a series of $10 \mathrm{~mL}$ separation volumetric flask solution by adding $0.5 \mathrm{~mL}$ of orphenadrine citrate $1 \times 10^{-3} \mathrm{~mol} / \mathrm{L}, 1 \mathrm{~mL}$ of sodium nitrite $1 \times 10^{-1} \mathrm{M}$ and between $(0.0-4.0 \mathrm{~mL})$ of 1-amino naphthalene $1 \times 10^{-3} \mathrm{M}$, then added $4 \mathrm{~mL}$ of ethanol and completed to $10 \mathrm{~mL}$ by bi-distillated water. The absorbance at $462 \mathrm{~nm}$ for every added of 1-amino naphthalene volume, against the blank of bi-distilled water was determined. It was found that the completed coloured complex formation was after $1 \mathrm{~mL}$ of 1 -amino naphthalene solution as it is shown in Fig. 2. The same work was repeated for studying the effect of sodium nitrite volume $0.1 \mathrm{M}$ in the volumes $0.1-1.2 \mathrm{~mL}$ and the best addition volume was $1 \mathrm{~mL}$ in this concentration (Fig. 3).

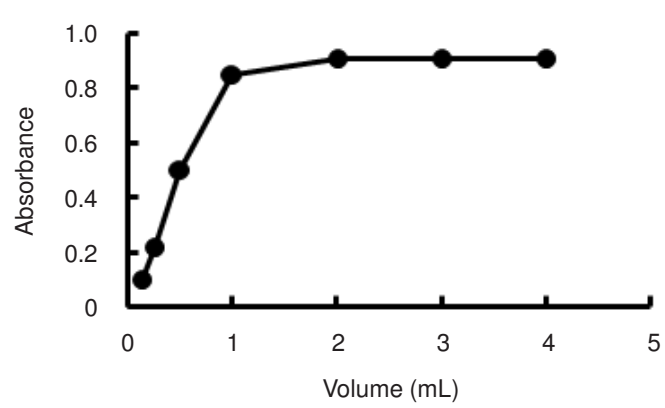

Fig. 2. Effect of volume 1-amino naphthalene

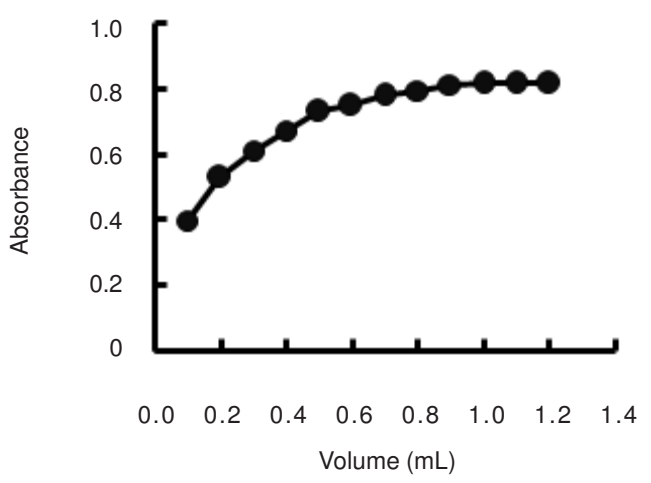

Fig. 3. Effect of volume sodium nitrite

Reaction ratios by molar ratio: To study the reaction ratios between orphenadrine citrate and 1-amino naphthalene, we made a series of $10 \mathrm{~mL}$ separation volumetric flask solutions by adding $0.5 \mathrm{~mL}$ of $1 \times 10^{-3} \mathrm{M}$ orphenadrine citrate and $1 \mathrm{~mL}$ of $1 \times 10^{-1} \mathrm{M}$ sodium nitrite, after we fixed a suitable volume and between $0.125-4.0 \mathrm{~mL}$ 1-amino naphthalene $1 \times$ $10^{-3} \mathrm{M}$, followed by the addition of $4 \mathrm{~mL}$ of ethanol and make up the volume to $10 \mathrm{~mL}$ by bi-distillated water. The absorbance was measured at $462 \mathrm{~nm}$ for every added of 1-amino naphthalene volume, against the blank of bi-distilled water. It was found that the reaction ratio (orphenadrine citrate: 1-amino naphthalene) was (1:2) (Fig. 4).

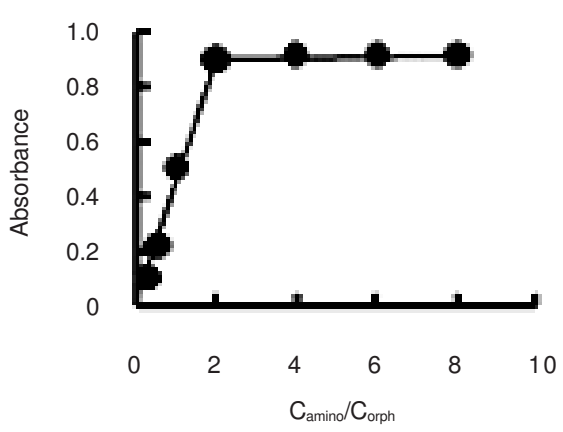

Fig. 4. Orphenadrine citrate and 1-amino naphthalene reaction ratios by molar ratio

Reaction ratios by continuous variation: To study the reaction ratios by continuous variation between orphenadrine citrate and 1-amino naphthalene, we made a series of $10 \mathrm{~mL}$ separation volumetric-flask solutions. each one contains $1 \mathrm{~mL}$ 
of sodium nitrite, $\mathrm{X} \mathrm{mL}$ solution of orphenadrine citrate $1 \times 10^{-3} \mathrm{M}$ and $\mathrm{Y} \mathrm{mL} 1$-amino naphthalene $1 \times 10^{-3} \mathrm{M}$ (always $\mathrm{X}+\mathrm{Y}=$ constant $)$ respectively, we heated, added $5 \mathrm{~mL}$ ethanol and completed to $10 \mathrm{~mL}$ by bi-distillated water. We measured the absorbance at $462 \mathrm{~nm}$ for every added of orphenadrine citrate and 1-amino naphthalene volume, against the blank bidistillated water. It was found that reaction ratio (orphenadrine citrate: 1-amino naphthalene) was (1:2) (Fig. 5).

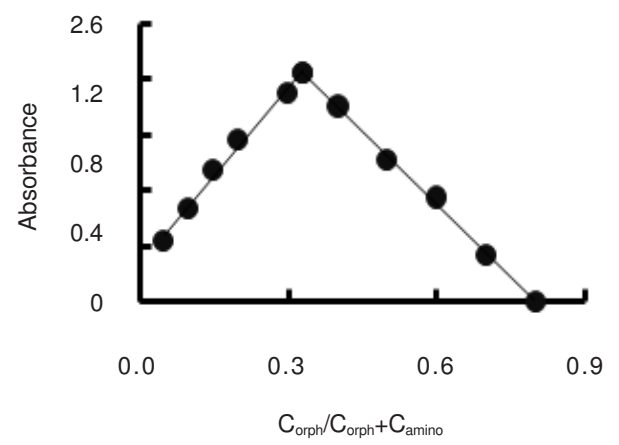

Fig. 5. Orphenadrine citrate and 1-amino naphthalene reaction ratios by continuous variation

Complex formation constant $\left(\log \mathbf{K}_{\mathbf{c}}\right)$ : The complex formation constant was calculated after the molar ratio and the continuous variation as presented in Table-1.

TABLE-1

COMPLEX FORMATION CONSTANT $\left(\log \mathrm{K}_{c}\right)$

\begin{tabular}{ccc}
\hline Method & $\log \mathrm{K}_{\mathrm{c}}$ & Average \\
\hline Molar ratio & 9.71 & 9.48 \\
Continuous variation & 9.24 & \\
\hline
\end{tabular}

Paracetamol analysis: After preparation of the stock solution we made series of $10 \mathrm{~mL}$ separation volumetric-flask solutions and scanned the spectrum in the range 200-400 nm against the blank of bi-distilled water and then calculated the first order derivative from the software program. It is found that paracetamol had a good absorbance at $264.17 \mathrm{~nm}$ where the coloured complex and other components had zero absorbance at this wavelength. Molar absortivity coefficient was $10104 \mathrm{~L} \mathrm{~mol}^{-1} \mathrm{~cm}^{-1}$, limit of detection and limit of quantification were: 0.22 and $0.66 \mu \mathrm{g} / \mathrm{mL}$ respectively. Sandell sensitivity was $0.075 \mu \mathrm{g} / \mathrm{cm}^{2}$.

Range and linearity of orphenadrine citrate: We studied the linearity orphenadrine citrate concentration at the optimal conditions where we made a series of $10 \mathrm{~mL}$ separated volumetric flasks each one contains $1 \mathrm{~mL}$ of 1 -amino naphthalene $2 \times 10^{-3} \mathrm{M}, 1 \mathrm{~mL}$ of sodium nitrite $1 \times 10^{-1} \mathrm{M}$ and variable concentration of orphenadrine citrate stock solution $1 \times 10^{-3}$ $\mathrm{M}$, the constant concentration of paracetamol was added and heated, added $4 \mathrm{~mL}$ ethanol and then completed to $10 \mathrm{~mL}$ by bi-distillated water, finally measured the absorbance at $462 \mathrm{~nm}$ for each concentration against the blank bi-distillated water. Fig. 6 presents the orphenadrine citrate spectra. The range of linearity was obeyed to Beers law in concentration 4.61-80.76 $\mu \mathrm{g} / \mathrm{mL}$ and the linearity is presented in Fig. 7 .

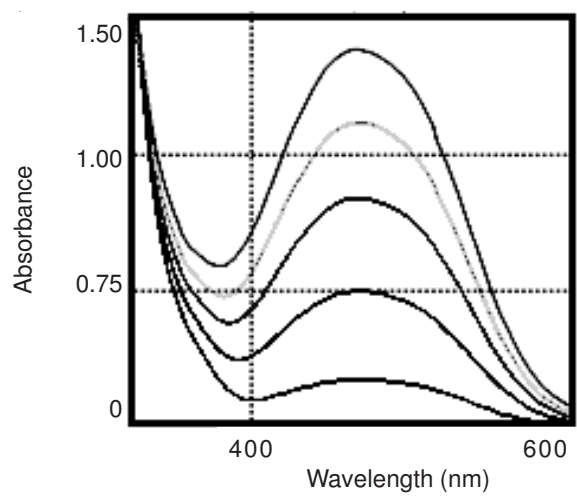

Fig. 6. Spectra of orphenadrine citrate complex

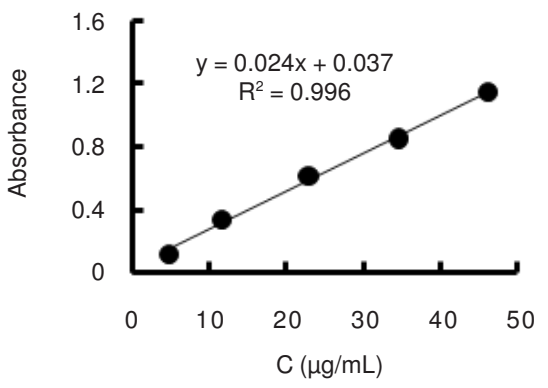

Fig. 7. Linearity of orphenadrine citrate

Range and linearity of paracetamol: The same work for studying paracetamol linearity was done by adding a constant concentration of orphenadrine citrate and the same precedent volumes of 1-amino naphthalene, sodium nitrite and variable concentration of paracetamol stock solution, using the first order derivative at $264.17 \mathrm{~nm}$ (Fig. 8). It is found that linearity was obeyed Beers law in concentration 0.75-30 $\mu \mathrm{g} / \mathrm{mL}$ and the linearity is presented in Fig. 9.

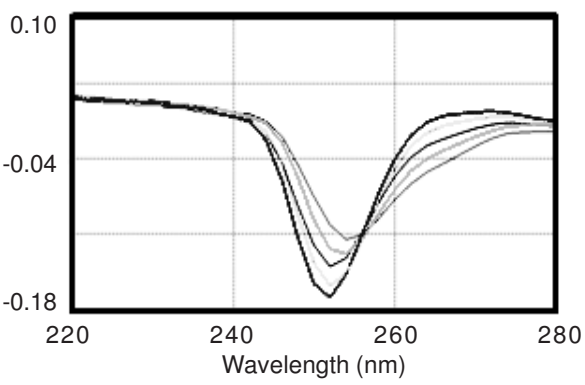

Fig. 8. First derivative spectra of paracetamol

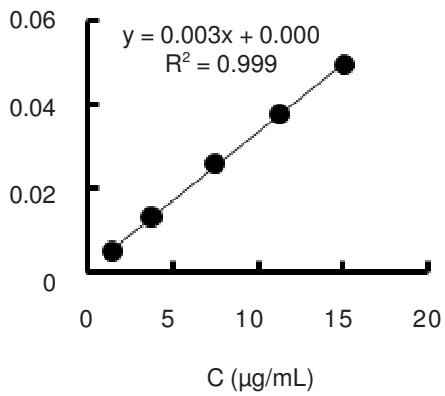

Fig. 9. Linearity of paracetamol 


\begin{tabular}{|c|c|c|c|c|c|c|c|c|c|c|c|c|}
\hline \multicolumn{13}{|c|}{$\begin{array}{c}\text { TABLE-3 } \\
\text { DETERMINATION OF PARACETAMOL AND ORPHENADRINE CITRATE IN } \\
\text { SOME SYRIAN TRADEMARKS TABLETS FORMULATIONS }\end{array}$} \\
\hline $\begin{array}{l}\text { Trade } \\
\text { name }\end{array}$ & Company & Drug & $\begin{array}{l}\text { Dose } \\
(\mathrm{mg})\end{array}$ & $\mathrm{X}_{1}$ & $\mathrm{X}_{2}$ & $\mathrm{X}_{3}$ & $\mathrm{X}_{4}$ & $\mathrm{X}_{5}$ & $\overline{\mathrm{X}}$ & $\begin{array}{c}\text { Recovery } \\
(\%)\end{array}$ & $\begin{array}{l}\text { RSD } \\
(\%)\end{array}$ & $\mathrm{LC}$ \\
\hline \multirow{2}{*}{ Tranpal } & \multirow{2}{*}{ Amrit } & Paracetamol & 450 & 449.7 & 449.70 & 449.7 & 448.2 & 449.7 & 449.40 & 99.86 & 0.14 & 0.83 \\
\hline & & Orphenadrine citrate & 35 & 34.9 & 34.90 & 35.4 & 35.4 & 34,0 & 34.92 & 99.77 & 1.63 & 0.70 \\
\hline \multirow{2}{*}{ Asiagesic } & \multirow{2}{*}{ Asia } & Paracetamol & 450 & 451.1 & 445.00 & 449.8 & 449.8 & 449.8 & 449.10 & 99.80 & 0.52 & 0.92 \\
\hline & & Orphenadrine citrate & 35 & 34.5 & 35.30 & 35.6 & 34.0 & 35.3 & 34.94 & 99.82 & 1.90 & 0.82 \\
\hline \multirow{2}{*}{ Myoflex } & \multirow{2}{*}{ Syphco } & Paracetamol & 450 & 449.7 & 450.59 & 449.7 & 449.7 & 451.1 & 450.14 & 100.03 & 0.14 & 0.78 \\
\hline & & Orphenadrine citrate & 35 & 34.5 & 34.90 & 34.5 & 35.0 & 35.8 & 34.94 & 99.82 & 1.52 & 0.65 \\
\hline
\end{tabular}

Table- 2 outlined the optimal parameters of the paracetamol and orphenadrine citrate.

TABLE-2

OPTIMAL SPECTROPHOTOMETRIC PARAMETERS OF THE PARACETAMOL AND ORPHENADRINE CITRATE

\begin{tabular}{lcc}
\hline \multicolumn{1}{c}{ Parameters } & Paracetamol & $\begin{array}{c}\text { Orphenadrine } \\
\text { citrate }\end{array}$ \\
\hline$\lambda_{\max }(\mathrm{nm})$ & 264.17 & 462 \\
Beer's law limit $(\mu \mathrm{g} / \mathrm{mL})$ & $0.75-30$ & $4.61-80.76$ \\
Molar absorptivity $(\mathrm{L} / \mathrm{mol} \mathrm{cm})$ & 12161 & 10104 \\
Sandell's sensitivity $\left(\mu \mathrm{g} / \mathrm{cm}^{2}\right)$ & 0.075 & 0.029 \\
Linear regression equation & $\mathrm{m}=0.003$ & $\mathrm{~m}=0.024$ \\
& $\mathrm{~b}=0.000$ & $\mathrm{~b}=0.037$ \\
Correlation coefficient & 0.999 & 0.996 \\
$\mathrm{LOD}(\mu \mathrm{g} / \mathrm{mL})$ & 0.22 & 0.89 \\
$\mathrm{LOQ}(\mu \mathrm{g} / \mathrm{mL})$ & 0.66 & 2.7 \\
Complex formation constant $\left(\log \mathrm{K}_{\mathrm{c}}\right)$ & - & 9.48 \\
\hline
\end{tabular}

Analysis of commercial tablets: The proposed method has been applied for the analysis of paracetamol and orphenadrine citrate in their commercial tablet products. Twenty tablets were grounded and determined the tablet average weight. A quantity of powder equal to $500 \mathrm{mg}$ paracetamol and $35 \mathrm{mg}$ orphenadrine citrate was transferred to $500 \mathrm{~mL}$ volumetric-flask and completed to volume with bidistillated water. The analyte was filtered and took a suitable volume to achieve the studied linearity. We added to it $1 \mathrm{~mL}$ 1 -amino naphthalene and $1 \mathrm{~mL}$ sodium nitrite, then heated a mixture solution at $50{ }^{\circ} \mathrm{C}$ for $6 \mathrm{~min}$, after that $4 \mathrm{~mL}$ of ethanol was added to make up the solution to $10 \mathrm{~mL}$ by bi-distillated water. Finally, the absorbance at $462 \mathrm{~nm}$ was measured and took the first order derivative from the application of the program at $264.17 \mathrm{~nm}$. There were no interferences between drugs and tablet excipients. Table- 3 presents the determination results of paracetamol and orphenadrine citrate in some Syrian commercial products.

\section{Conclusion}

We developed a new method which is suitable for the identification and quantification of the binary combination of paracetamol and orphenadrine citrate in Syrian tablets formulation.

A good percentage of recovery shows that the method can be successfully used in a routine basis. The proposed method is simple, sensitive, rapid, specific, a little cost and could be applied for quality control of paracetamol and orphenadrine citrate.

\section{ACKNOWLEDGEMENTS}

This work was financially and technically supported by Ministry of High Education through University of Aleppo, Faculty of Science, Department of Analytical Chemistry in the University of Aleppo, Aleppo, Syria.

\section{REFERENCES}

1. The British Pharmacopoeia, British Pharmacopoeia Commission Office, Vol. I and II, p 4363, 3456 (2009).

2. L. Srathaphut and N. Ruangwises, Yakugaku Zasshi, J. Pharm. Soc. (Japan), 120, 1723 (2007).

3. N.W. Ali, M.R. Elghobashy, M. Gamal and M. Abdelkawy, J. First International Pharm. Sciences Conference (2009).

4. B.R. Shrestha and R.R. Pradhananga, J. Nepal Chem. Soc., 24, 39 (2009).

5. P. Ravikumar, M.M. Krishna, P.B. Prakash, B.A. Kumar and P. Madhusudhan, E-J. Chem., 3, 134 (2006).

6. H.M. Saleh, M.M. EL-Henawee, G.H. Ragab and S.S. Abd El-Hay, J. Spectrochim. Acta A, 67, 1284 (2007).

7. S.A. Shama, J. Pharm. Biomed. Anal., 30, 1382 (2002).

8. S. Narayan, P. Kumar, R.K Sindhu, A. Tiwari and M. Ghos, Der. Pharma Chem., 1, 72 (2009).

9. D.N. Haj-Ali and I.I. Hamdan, Saudi Pharm. J., 18, 233 (2010).

10. M.S. Arayne, N. Sultana and F.A. Siddiqui, J. Chin. Chem. Soc., 56, 169 (2009).

11. J.T. Franeta, D. Agbaba, S. Eric, S. Pavkov, M. Aleksic and S. Vladimirov, IL Farmaco, 57, 709 (2002).

12. D.D. Borkar, V.P. Godse, Y.S. Bafana, A.V. Bhosale, Int. J. Chem. Tech. Res., 1, 667(2009).

13. N.H. Krishnan, V. Gunasekaran, C. Roosewelt, K. Kalaivani, S. Chandrasekaran and V. Ravichandiran, Asian J. Chem., 20, 2557 (2008).

14. K. Kachrimanis, D.E. Braun and U.J. Griesser, J. Pharm. Biom. Anal., 43, 407 (2007).

15. M. Knochen, J. Giglio and B.F. Reis, J. Pharm. Biomed. Anal., 33, 191 (2003).

16. A.B. Moreira, H.P.M. Oliveira, T.D.Z. Atvars, I.L.T. Dias, G.O. Neto, E.A.G. Zagatto and L.T. Kubota, J. Anal. Chim. Acta, 539, 257 (2005). 